\title{
HIGH-RATE REEL-TO-REEL CONTINUOUS COATING OF BIAXIALLY TEXTURED MAGNESIUM OXIDE THIN FILMS FOR COATED CONDUCTORS*
}

M. P. Chudzik, R. A. Erck, and U. Balachandran

Energy Technology Division, Argonne National Laboratory

Argonne, IL 60439

Z.P. Luo and D.J. Miller

Materials Science Division, Argonne National Laboratory

Argonne, IL 60439

C. R. Kannewurf

Department of Electrical and Computer Engineering, Northwestern University

Evanston, IL 60208

December 1999

The submitted manuscript has been created by the University
of Chicago as Operator of Argonne National Laboratory
(“Argonne") under Contract No. W-31-109-ENG-38 with the
U.S. Department of Energy. The U.S. Govemment retains for
itself, and others acting on its behalf, a paid-up, nonexclusive,
irrevocable worldwide license in said article to reproduce,
prepare derivative works, distribute copies to the public, and
perform publicly and display publicly, by or on behalf of the
Government.

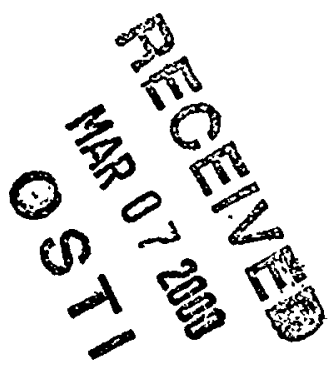

Paper to be presented at Sixth International Conference on Materials and Mechanisms of Superconductivity and High-Temperature Superconductors, Houston, TX, Feb. 20-25, 2000.

*Work supported by the U.S. Department of Energy (DOE), Energy Efficiency and Renewable Energy, as part of a DOE program to develop electric power technology, under Contract W-31-109-Eng-38, and by the National Science Foundation through the Science and Technology Center for Superconductivity (Grant No. DMR 91-20000). 


\section{DISCLAIMER}

This report was prepared as an account of work sponsored by an agency of the United States Government. Neither the United States Government nor any agency thereof, nor any of their employees, make any warranty, express or implied, or assumes any legal liability or responsibility for the accuracy, completeness, or usefulness of any information, apparatus, product, or process disclosed, or represents that its use would not infringe privately owned rights. Reference herein to any specific commercial product, process, or service by trade name, trademark, manufacturer, or otherwise does not necessarily constitute or imply its endorsement, recommendation, or favoring by the United States Government or any agency thereof. The views and opinions of authors expressed herein do not necessarily state or reflect those of the United States Government or any agency thereof. 


\section{DISCLAIMER}

Portions of this document may be illegible in electronic image products. Images are produced from the best available original document. 


\title{
High-Rate Reel-to-Reel Continuous Coating of Biaxially Textured Magnesium Oxide Thin
} Films for Coated Conductors*

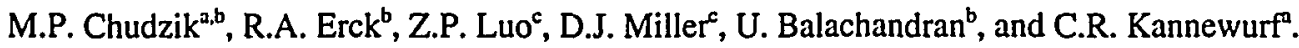 \\ 'Department of Electrical and Computer Engineering, Northwestern University, Evanston, IL 60208 USA \\ 'Energy Technology Division, Argonne National Laboratory, Argonne IL 60439 USA \\ 'Materials Science Division, Argonne National Laboratory, Argonne IL 60439 USA
}

Biaxially textured thin films of magnesium oxide $(\mathrm{MgO})$ were deposited by electron beam evaporation at deposition rates of $0.6 \mu \mathrm{m} / \mathrm{min}$ on moving Ni-based alloy tapes as oriented buffer layers for coated conductors. Moving substrates were inclined with respect to the atomic vapor and translated through collimated dual vapor sources. Growth anisotropy in the MgO and self-shadowing effects due to the inclined angle combine to create biaxial texture in the deposited thin films. MgO films grown to a thickness of $2.0 \mu \mathrm{m}$ with this inclinedsubstrate deposition technique have yielded in-plane textures of $10-12^{\circ}$ full-width half-maximum (FWHM). Results of a parametric study on the in-plane texture in short-length static-mode samples are presented, along with preliminary results of long-length samples deposited under translating conditions.

\section{Introduction}

The next-generation wire technology based on high-temperature superconductors requires a biaxially textured template layer on to which the superconductor will be coated. These template layers will need to be lattice-matched, chemically compatible, and economically feasible for lengths up to a $1 \mathrm{~km}$. A major hurdle to date in bringing these wires to market has been the slow deposition rate and/or complex deposition geometry needed to deposit biaxially textured template layers.

This study investigates the processing dependence of texture development in magnesium oxide $(\mathrm{MgO})$ films deposited by inclined substrate deposition (ISD) in order to optimize the deposition parameters required for continuous coating. ISD of $\mathrm{MgO}$ has been proven effective in creating shortlength biaxially textured $\mathrm{YBCO}$ coated conductors.[1] Half-meter biaxially textured magnesium oxide has been deposited by using a collimated-flux inclined substrate deposition (CFISD) geometry with feed rates of $6.1 \mathrm{~cm} / \mathrm{min}$.

-Work supported by the U.S. Department of Energy (DOE), Energy Efficiency and Renewable Energy, as part of a DOE program to develop electric power technology, under Contract W-3t-109-Eng-38, and by the National Science Foundation through the Science and Technology Center

for Superconductivity (Grant No. DMR 91-20000).
The texture in the $\mathrm{MgO}$ thin films was evaluated with four-circle $x$-ray diffraction and selected area electron diffraction (SAED). Growth morphology and structure was investigated by transmission electron microscopy (TEM).

\section{Experimental Method}

Long-length Hastelloy-C tapes were ultrasonically cleaned in acetone and methanol prior to loading in a reel-to-reel continuous deposition system. The reel-to-reel system was designed to allow simultaneous deposition on two tapes. The feed mechanism and take-up reel were designed to put the as-coated $\mathrm{MgO}$ tape in compression with < $5 \%$ strain. The tapes were inclined with respect to the atomic vapor at $40^{\circ}$ from the substrate normal. The atomic vapor was created with a dual electron beam evaporation system. Evaporation was conducted in two zones; each containing a group of collimators that restricted the angular variance of the atomic flux to $<10^{\circ}$. The feed rate through the two collimated deposition zones was adjusted such that $\mathrm{MgO}$ was deposited to a thickness of $1.0 \mu \mathrm{m}$ in a single pass. The deposition rate for continuous coating was $0.6 \mu \mathrm{m} / \mathrm{min}$. 


\section{Results and Discussion}

Cross-sectional TEM coupled with selected area diffraction allowed the investigation of texture development in ISD-MgO as a function of thickness through static samples (see Fig. 1). From intensityversus-thickness plots of dark-field photomicrographs, the coalescence zone of $\mathrm{MgO}$ into textured films occurs at $=900 \mathrm{~nm}$. In-plane texture of the $\mathrm{MgO}$ on static samples exhibits little dependence on the deposition rate as shown in fig. 2. Deposition on static samples also shows that inplane texture improves with an increase in sample inclination with respect to the vapor source; this in turn inclines the (200) face, which grows toward the vapor (see Fig. 3).

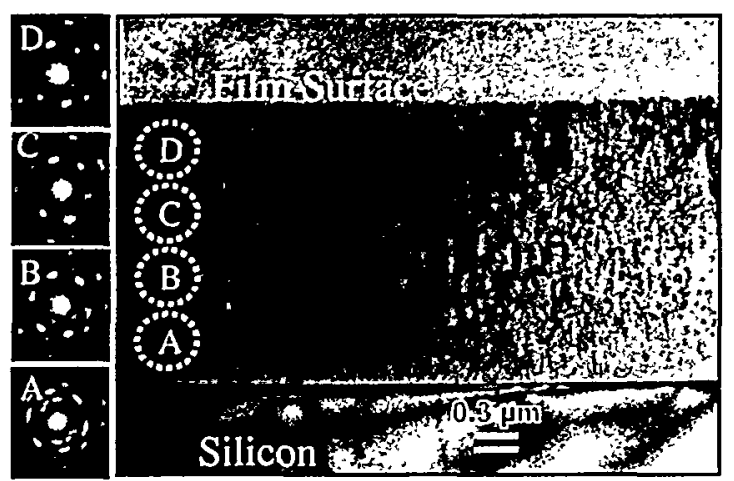

Figure 1: TEM photomicrograph of a static sample on $\mathrm{Si}$ with SAED patterns at various film thicknesses.

The average in-plane FWHM of a $0.5-\mathrm{m}$ tape deposited under continuous conditions as measured from pole figures was $24.4^{\circ}$. This value is the average FWHM measured from 10 positions along the tapes approximately every $5 \mathrm{~cm}$. The standard deviation of the FWHM was $1.05^{\circ}$ with the best value equal to $23.0^{\circ}$; the highest FWHM was $26.1^{\circ}$. These values are slightly larger than expected from the use of $10^{\circ}$ collimators, however the measured FWHM are from films that are considerably thinner than the static samples and the surface texture is expected to be much sharper than the "bulk" value. Work in progress is addressing this issue by evaluating these layers with a thick homoepitaxial layer to confirm the quality of the texture surface of the CF-ISD MgO films.

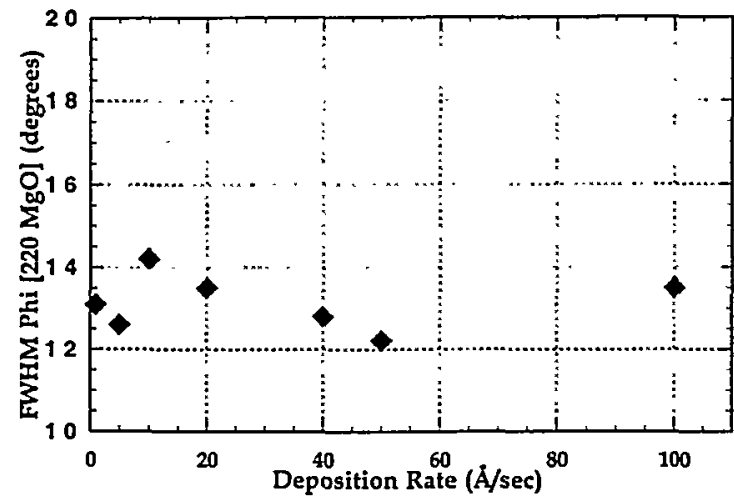

Figure 2: In-plane texture of ISD-MgO vs. deposition rate for $2.5 \mu \mathrm{m}$ thick films.

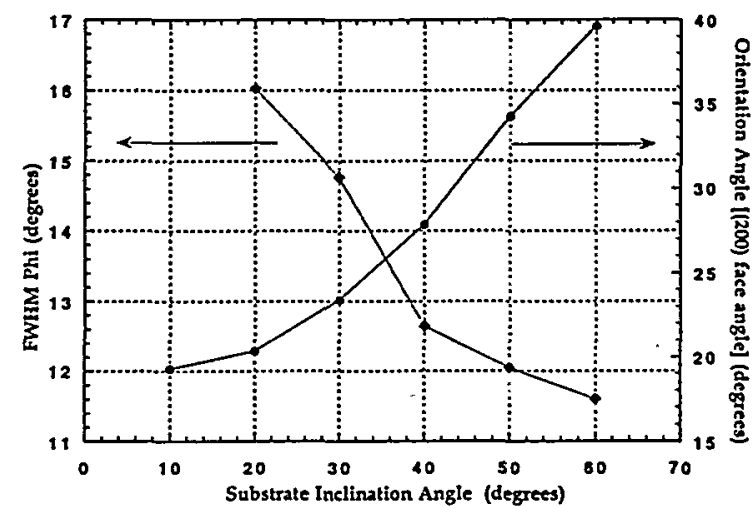

Figure 3: In-plane FWHM and (200) face orientation of ISD-MgO vs. substrate inclination angle in static samples ( $2.5 \mu \mathrm{m}$ thick).

\section{Conclusions}

Biaxially textured $\mathrm{MgO}$ template layers were deposited on continuously moving Hastelloy-C tapes to a length of $0.5 \mathrm{~m}$ by using a collimated-flux inclined substrate deposition (CF-ISD) system. The feed rate of the tapes was $6.1 \mathrm{~cm} / \mathrm{min}$ over a total deposition zone of $10 \mathrm{~cm}$. The resultant in-plane texture averaged $24.4^{\circ} \mathrm{FWHM}$ as measured from phi scans of the (220) reflection at $5-\mathrm{cm}$ intervals.

\section{Reference}

1. M. Bauer, R. Semerad, and H. Kinder, IEEE Trans. on Appl. Supercond., Vol. 9, No. 2, pp. 1502-1505 (1999) 